\title{
Bibliotecas como makerspace: oportunidades de implementação a partir de um caso prático
}

\author{
Rocelle Gil Santos \\ Graduada em Biblioteconomia \\ Universidade Federal de Santa Catarina \\ rocellegil@gmail.com \\ Ana Clara Candido \\ Doutora em Avaliação de Tecnologia \\ Universidade Federal de Santa Catarina \\ acc.anaclara@gmail.com
}

Libraries as makerspace: implementation opportunities from a practical case

\section{Resumo}

Na década de 70, ocorre o surgimento da cultura do "faça-você-mesmo", conhecida como cultura maker ou movimento maker, por se compreende que qualquer pessoa poder produzir, consertar, fabricar, melhorar ou criar algo, podendo utilizar a tecnologia, a exemplo da web ou mesmo ferramentas manuais. Desse modo, os makerspaces surgiram com a percepção de ser um espaço para criações e desenvolvimento de ideias, projetos e que por meio deles pudesse também ser compartiIhado conhecimento digital entre as pessoas. Nesta pesquisa, tem-se o objetivo de analisar as ações utilizadas na implementação de makerspace em bibliotecas na prática como subsídio para a proposta de um guia preliminar para futuras implementações. Do ponto de vista dos objetivos, a pesquisa se caracterizada como exploratória e descritiva. Entre os resultados, verifica-se o papel da biblioteca no desenvolvimento da comunidade, melhorando o acesso à informação e a participação dos usuários. Desta forma, a implementação de um espaço maker proporcionará mais atratividade para a biblioteca, além de fortalecer a troca de informação, conhecimento, colaboração e experimentação. Esta troca poderá contribuir para a utilização de métodos que podem trazer eficácia, retribuindo para além da criação de espaços, podendo ser utilizado para elaboração de novos serviços ou melhorias de iniciativas institucionais e profissionais promovendo um "upgrade" ao ambiente.

Palavras-chave

Biblioteca. Inovação. Makerspaces. Design Thinking.

\begin{abstract}
The 1970s are the backdrop to "do-it-yourself" culture, known as culture maker or movement maker, understood by anyone to be able to produce, to repair, to manufacture, to improve or to create something by using technology, such as the web or even hand tools. In this way, the makerspaces emerged with the perception of being a space for creation and development of ideas, projects and through them could also be shared digital knowledge among people. In this research the aims to analyze the actions used in the implementation of the makerspace in libraries in practice as a subsidy for the proposal of a preliminary guide for future implementations. The research is characterized as descriptive and exploratory. Among the results, the role of the library in the development of the community is verified, improving the access to the information and the accessibility of the individuals. In this way, the implementation of a space maker will provide more attractiveness to the library, in addition to
\end{abstract}


strengthening the exchange of information, knowledge, collaboration and experimentation. This exchange may contribute to the use of methods that can bring effectiveness, rewarding beyond the creation of spaces, and can be used to elaborate new services or improvements of institutional and professional initiatives promoting an "upgrade" to the environment.

\section{Keywords}

Library. Innovation. Makerspaces. Design Thinking.

\section{INTRODUÇÃO}

Entre as possibilidades advindas do desenvolvimento tecnológico em relação à internet, está a conectividade entre as pessoas e o acesso à informação e ao conhecimento. Este contexto propicia inovações desde criações digitais até à expansão do compartilhamento de informações e atualmente vem trazendo um conceito mais pedagógico, fazendo com que as instituições como bibliotecas também inovem e participem.

A cultura do "faça-você-mesmo", surgida na década de 70, é atualmente conhecida como cultura maker ou movimento maker. Designa deste termo a ideia de que qualquer pessoa pode produzir, consertar, fabricar, melhorar ou criar algo podendo utilizar a tecnologia, a exemplo da web ou mesmo ferramentas manuais. Desse modo, os makerspaces surgiram com a percepção de ser um espaço para criações e desenvolvimento de ideias, projetos e que por meio deles pudesse também ser compartilhado conhecimento digital entre as pessoas.

Portanto, makerspace é um termo em inglês que significa espaços para fabricantes, ou seja, espaços onde os makers (criadores) possam criar, fabricar, "dar vida" a seus projetos.

Cardins (2012) afirma que, ao longo dos anos, a filosofia do "faça-você-mesmo" tem se adaptado a uma extensa diversidade de áreas de atuação, porém, sempre baseada em muita criatividade e compartilhamento de informações, o que define a cultura do "façavocê-mesmo". Assim, o movimento maker acaba sendo uma dimensão da cultura ou movimento "faça-você-mesmo" também conhecida como Do It Yourself (D/Y) - "faça-vocêmesmo".

Para a utilização de um espaço maker ou para ser "considerado um maker" é válido que se compartilhem e troquem informações e ideias com o intuito de benefício a toda a sociedade sem que se faça distinção de qualquer perfil de indivíduo.

Para Macedo e Santos (2016, p. 72), makerspaces são “[...] espaços utilizados para as mais diversas atividades, cursos e serviços relacionados à informação, cultura e desenvolvimento de habilidades de pesquisa e uso de novas tecnologias". A autoras destacam que as bibliotecas poderão torna-se também o "centro das criações de novas tecnologias", quando disponibilizarem ferramentas e equipamentos tecnológico como uma impressora 3D.

Existem outros espaços como fablab e coworking que também podem ser considerados makerspaces que objetivam a troca de informações, a colaboração e o compartilhamento de conhecimento digital, porém, cada um tem sua característica.

Toda fablab deve seguir critérios, como dispor de uma certa quantidade de equipamentos, a exemplo da impressora 3D que é requisito indispensável de acordo com as diretrizes criadas pelo Massachusetts Institute of Technology (MIT). Outro critério fundamental é que devem ser "conectadas" para manter a troca de conhecimento digital de acordo com as diretrizes do MIT. 
Coworking são espaços multifuncionais para trabalhos compartilhados que os profissionais procuram, por se tratar de um local estruturado conforme sua necessidade, podendo ter internet, café e até divisões de custos, além de outras atividades como games, pilates, entre outras.

É um espaço com potencial para ter várias empresas conectadas e colaborativas desde a freelancer, profissionais liberais e quem mais tenha interesse e que saiba colaborar, sendo diferente de um escritório convencional ou da própria casa, no caso dos profissionais que trabalham em suas próprias residências. "Espaços de coworking foram originalmente formados como uma alternativa ao trabalho de um escritório em casa, onde é muito fácil tornar-se isolado, ou para o café da vizinhança, onde é muito fácil se distrair" (LUMLEY, 2014, p. 51).

Observa-se então, que os makerspaces podem ser espaços de criação que permitem inovações, ou seja, a inserção de outros espaços como fablab ou coworking, ou até mesmo a criação de novos espaços de acordo com a necessidade de seu público ou adaptação conforme sua estrutura ou sua realidade.

Para Litts (2015, p. 01, tradução nossa), "Makerspace são lugares onde a cultura do fazer acontece na comunidade".

Por fim, o objetivo do presente estudo é analisar as ações utilizadas na implementação de makerspace em bibliotecas na prática como subsídio para a proposta de um guia preliminar para bibliotecas.

\section{ESPAÇOS DE CRIATIVIDADE E INTERAÇÃO}

De acordo com Cavalcanti (2013), Cavallini (2014), Litts (2015), Maravilhas (2016) e Martins (2017), os Makerspaces são espaços para criação de ideias, trocas de informações sobre serviços, projetos, novos conceitos, entre outros. Portanto, pode ser considerado qualquer espaço que tenha o objetivo de compartilhar conhecimento e, até mesmo, o desenvolvimento digital, entre outras atividades.

Os makerspaces podem conter laboratórios de fabricação ou ser apenas um espaço de trabalho. Esses espaços podem ser privados ou comunitários, dependendo do objetivo do makerspace. Outro propósito é que não se exclua ninguém, independentemente de sua característica.

Apresentam também definições distintas, mesmo assim, suas considerações são semelhantes devido ao surgimento e a similaridade com os hackerspace, coworking e fablab.

Nas palavras de Martins (2017, p. 59), "nas últimas décadas, temos assistido à proliferação de espaços alternativos de pesquisa, produção e aprendizado colaborativos, tais como hackerspaces, fablabs, makerspaces e laboratórios cidadãos, entre outras denominações".

De acordo com o Abdo e Amaral [20--?], o conceito makerspace surgiu do movimento maker, termo popularizado por Dale Dougherty, fundador da revista Make em 2005. Dougherty em entrevista para Abdo e Amaral [20--?] diz "que o movimento representa novas maneiras de produzir objetos e conectá-los em rede".

De acordo com Litts (2015, p. 04, tradução nossa), "makerspaces emergiram do mesmo movimento do tinkerer, do-it-yourself (DIY) que os espaços de hackers nasceram".

O CEO da empresa TechShop Hatch (2013) considera que o movimento maker teve origem do Do It Yourself (DIY) conhecida como cultura do "faça-você-mesmo" e trazendo como conceito fazer, compartilhar, dividir, doar, aprender, equipar, brincar, participar, apoi- 
ar e mudar. Os autores Gallo (2010) e Cardins (2012) dizem que a cultura do "DIY" se iniciou nos anos 70 por intermédio do movimento punk em relação à comercialização de suas músicas, gerando, então, contrariedade que levou o punk à independência, acarretando o "faça você mesmo".

Cardins (2012) explica que essa ação propiciou novas oportunidades que adentrassem a novas áreas de atuação de forma espontânea. Desta forma, permitindo o desenvolvimento da Web, através dos blogs e mídias digitais. No entanto, trazendo sua filosofia baseadas em criatividade e compartilhamento de informações.

A partir do conceito do Do It Yourself, apresentado pelos autores, iniciou-se este processo, e considera-se que o "boom" ocorre em 1990 com o surgimento da Web.

Deste modo, observa-se que o desenvolvimento tecnológico, sobretudo, a Web contribuiu ainda mais para o surgimento desses espaços, sendo inclusive um dos principais responsáveis por esse movimento devido ao compartilhamento de informações, trazendo novas possibilitadas e conectividade entre as pessoas. E, assim, levou a cultura DIY para um modelo mais pedagógico como o "Do It together".

Ainda compreendendo o significado de maker, Cavallini (2014) da revista "HSM Management" apresenta o Manifesto do movimento maker com nove definições resumidas que é chamado de "Os 9 mandamentos do Movimento Maker" retratado a seguir:

\footnotetext{
Make - Faça É o que define o ser humano. Share - Compartilhe É o método pelo qual o maker (fazedor) se sente completo. Give - Doe Há poucas coisas mais satisfatórias do que, com desprendimento, doar algo que você fez. Learn - Aprenda É preciso aprender a fazer. $E$, por mais que você se torne um mestre artesão, sempre há novas técnicas, materiais e processos. Tool up - Aparelhe-se Você precisa ter acesso às ferramentas corretas para o projeto que tem em mãos. Invista e desenvolva acesso a elas, que nunca foram tão baratas e fáceis de usar. Play - Brinque Divirta-se com o que está fazendo e você ficará surpreso, animado e orgulhoso do que vai descobrir. Participate - Participe Una-se ao movimento maker e tenha acesso a pessoas a sua volta que estão descobrindo a alegria de fazer. Support Apoie Esse é um movimento e ele exige apoio emocional, intelectual, financeiro, político e institucional. Change - Mude Acolha a mudança que vai acontecer naturalmente em sua jornada de maker. (CAVALLINI, 2014, p. 26).
}

Litts (2015) afirma que para ser um maker não necessariamente precisa ter uma idade específica, na medida em que diversas pessoas com idades mais jovens desde crianças até pessoa aposentadas podem utilizar os espaços. Porém, alguns espaços têm suas necessidades específicas e um perfil de público diferente, e outros com espaços acessíveis a qualquer pessoa sem especificidade. No entanto, independentemente da idade, a resposta é que as pessoas são o núcleo do makerspaces.

Martins (2017) salienta que os makerspaces podem também apresentar custos na utilização de suas máquinas, porém, essas se mantêm abertas ao público sem distinção, considerando como um modelo de serviço, devido ao conceito de colaboração trazido do DIY.

Borges (2016) já explica que, para o sujeito se intitular maker, é necessário possuir competências e habilidades que o auxilie na resolução de problemas mais complexos. Além disso, por meio dos desafios encontrados no processo do fazer, acabam por adquirir aprendizado. Além de construir novos conhecimentos e logo compartilhando tanto sua produção quanto o conhecimento novo desde o processo inicial, ocasionando novas e melhores soluções. 
Por fim, para conceituar o makerspace é importante conhecer a cultura maker, para a compreensão de todo processo e de suas características.

\section{DESIGN THINKING COMO MÉTODO DE SUPORTE PARA A CRIAÇÃO DE MAKERSPACE}

O design para Vianna et al. (2012) aguçou o interesse de empresário e gestores devido à observação do designer, em seu modo de perceber as coisas, o entorno e a forma que o profissional examina as necessidades das pessoas. Além do processo que desenvolve o projeto e o trabalho, promovendo o conforto e a satisfação do ser humano, o design acaba se expandindo a novos horizontes, tanto na gestão empresarial quanto para instituições.

Na obra de Brown (2010), o design thinking ou Design se difere no formato do antigo, no qual é configurado em um modelo que os designers dão vida aos projetos. Trata-se de um modelo mental de conceitos válidos, com aplicabilidade a qualquer cenário, pessoas e negócio, podendo ser aprendido por qualquer pessoa.

Martin (2010) explica que experiências e posturas são essenciais características para se tornar um design thinking, além da sensibilidade e das habilidades. Ao longo do tempo, são construídas experiências que organizadas em pensamentos permitem a compreensão do entorno ou o mundo através de ferramentas. Resultante disto, a postura é a forma como observamos o mundo e o nosso objetivo nele.

Martin (2010) afirma que o design thinker, ao invés de se deixar intimidar, busca validez no conhecimento mesmo que precise confrontar a cultura da organização, considerando o domínio de ferramentas, a capacidade de analisar o passado, prever o futuro e enxergando os recursos que outros possam não enxergar, tendo o designer grande capacidade de observação.

Vianna et al. (2012) afirmam que o design thinking tem o pensamento abdutivo diferente do empresarial, posto que ele formula os questionamentos através da percepção e compreensão dos fenômenos, formula perguntas que serão respondidas a partir das informações coletadas durante a observação.

Segundo a obra Design Thinking de Ambrose (2011), o significado de design thinking é a forma de pensar do design, que é importante para o desenvolvimento de um determinado trabalho. $\mathrm{O}$ autor trata este termo de coletas de informação como briefing (conjunto de informações coletadas para um determinado trabalho), que é realizado junto com o cliente do início ao fim. A sua importância se dá na solução do problema e no processo criativo do trabalho, viabilidade e orçamento.

Conforme já mencionado, os makerspaces são espaços onde se pode construir, criar e desenvolver ideias e projetos. De acordo as necessidades apresentadas pelo cliente/usuário, uma análise seria feita a partir do perfil deste e, a partir do resultado coletado da observação, define-se o tipo de makerspace mais adequado. Com isso, a ferramenta design thinking pode ser o método adequado para o desenvolvimento do espaço, por ter o foco direcionado ao usuário e às suas necessidades, permitindo que o cliente/usuário seja incluído em todo processo de desenvolvimento.

Brown (2010) faz também uma abordagem centrada no humano, prevalecendo o equilíbrio nas perspectivas dos usuários, da tecnologia e dos negócios, dado que o design thinking é uma ferramenta também para resolver problemas e que é ajustável a qualquer circunstância. A criação de makerspace pode ser viável com o uso da ferramenta ou método design thinking, uma vez que visa o humano e tem como característica a observação. 
Visto que o ambiente maker em uma biblioteca traz como fundamento a conexão, o compartilhamento, o conhecimento e a experimentação, a ferramenta design thinking tende a ser a mais adequada como apoio para a gestão e implementação desses espaços.

\section{PROCEDIMENTOS METODOLÓGICOS}

Do ponto de vista dos objetivos, este estudo caracteriza-se como exploratório e descritivo. A investigação teve como base o levantamento bibliográfico para melhor compreensão dos conceitos como fonte secundária de informações. Além desse levantamento, foi realizada entrevista com um guia semiestruturado para a coleta de informações de instituições que mantêm de makerspace.

O referencial teórico está pautado no levantamento bibliográfico a partir dos conceitos de makerspace, fablab e coworking devido às suas similaridades. Os termos como "bibliotecas como makerspace", "makerspace em bibliotecas", "bibliotecas com makerspace", "bibliotecas com espaços criativos", "bibliotecas com espaços do fazer", "bibliotecas com espaços de criação", "bibliotecas com espaços mão na massa", "espaços criativos em bibliotecas", "espaços do fazer em bibliotecas", "espaços inovadores em bibliotecas" e terminologias em inglês foram utilizados com a finalidade de aumentar a precisão na recuperação de informações. Estas terminologias foram usadas e algumas descritas anteriormente para meIhor identificação, visto que em algumas pesquisas essas bibliotecas poderiam reconhecer esses espaços com outro termo.

Ferramentas tecnológica como a Web, o motor de busca Google Acadêmico, algumas bases de dados, encontradas dentro no portal da biblioteca universitária, Portal de Periódico da CAPES e Scielo foram utilizadas para a busca de informações que nos permitissem a pesquisa.

Definidos e compreendidos os conceitos, realizou-se a próxima etapa, identificação de casos práticos de bibliotecas que tivessem makerspace ou algum espaço do fazer. Entre os casos práticos identificados, a "Casa Thomas Jefferson" serviu de base para a análise empírica deste estudo. Destaca-se que foram identificados outros casos, porém, pela falta de resposta na participação desta pesquisa, não foi possível inclui-las nesta análise.

Assim, realizou-se uma entrevista com guia semiestruturado contendo treze questões. O tempo da entrevista foi de aproximadamente trinta minutos via videoconferência com a gestora da instituição. Também houve uma visita in loco, além de interação via e-mail anteriormente à realização da entrevista.

A entrevista e os dados coletados permitiram a criação de um guia preliminar de implementação de makerspace em bibliotecas que será apresentado posteriormente.

\section{A IMPLEMENTAÇÃO DE MAKERSPACE NA CASA THOMAS JEFFERSON}

Nesta seção, apresenta-se de forma sintetizada as principais informações coletadas da escola Casa Thomas Jefferson de Brasília (2018), através da entrevista realizada via videoconferência, constituindo fonte primária dos dados da pesquisa.

A Casa Thomas Jefferson surgiu em 1963. Trata-se de uma Centro Binacional sem fins lucrativos, com objetivo de fornecer intercâmbio entres as culturas americana e brasileira, com certificação de excelência da Embaixada dos Estados Unidos.

Em 2016, surge a primeira makerspace da Casa Thomas Jefferson, dentro da biblioteca. O Presidente norte-americano Barack Obama, visando resgatar habilidades do fazer co- 
mo oportunidade de desenvolver mão de obra qualificada e fazer com que escolas, bibliotecas e biblioteca públicas tivessem esses tipos de espaços, criou o International Day of Maker, desenvolvendo um Maker Faire dentro da Casa Branca em seu primeiro mandato. Com a grande repercussão que teve do episódio, esse evento acabou se configurando mais como um fazer com objetivos pedagógicos, procurando realmente criar essa onda de fomentar habilidades do século XXI, que são configuradas como atividades "mão na massa" ou "faça você mesmo", colocando em prática o saber, que fosse aplicado desde o ensino fundamental, trazendo a importância do vínculo de escolas, bibliotecas escolares e bibliotecas públicas com esses espaços. Mudando, então, o modelo "Do it Yourself" para "Do it together".

Com a ideia de levar essa iniciativa a todos espaços americanos que façam esse vínculo entre a cultura local com a cultura americana em todo o mundo, a escola Casa Thomas Jefferson, conhecida como um desses espaços, foi convidada para ser a piloto no Brasil.

Em parceria, o Departamento de Estado Americano e a Casa Thomas Jefferson juntaram seus recursos, tendo um aporte financeiro de recursos igualitário de ambos para criar esse makerspace. A ideia do projeto era criar um makerspace junto à biblioteca de Brasília, com o intuito de formar um complexo de aprendizado. O projeto em parceria, iniciou em 2014, mas só 2016 foi efetivado.

Desde então, foram feitos trabalhos de conscientização para um novo perfil de biblioteca. Atividades "mão na massa" e "não fazer só pelo fazer" eram desenvolvidas por todos espaços da biblioteca e da Casa Thomas Jefferson, caracterizando-se como do perfil maker. O seu principal objetivo era a mudança de modelo mental do que era a biblioteca, por isso essas atividades eram bem menores devido aos equipamentos que ainda não dispunham. Então, o trabalho de conscientização e de informação era feito também com todos os profissionais que trabalhavam na Casa Thomas Jefferson, e envolviam outras pessoas, tais como professores, alunos, pais, comunidade e bibliotecários.

Com esse trabalho estruturado de mudança de modelo mental, a biblioteca também teve de se adequar e passou a seguir um novo conceito de Resource Centers ( $R C$ ), com finalidade primária de estimular a colaboração, a exploração e o fascínio, trazendo também uma forma de educação por meio da facilitação, em oposição à atuação depositaria como era o perfil anterior, além de facilitar o idioma através de atividades em geral.

E, assim, o novo makerspace foi criado com o objetivo de fomentar o aprendizado por meio de "atividades mão na massa", proporcionando oportunidades para desenvolvimento de projetos, inovação, empreendedorismo, desenvolvimento de habilidades, criatividade e trabalho em grupo, trazendo uma proposta de um hub de inovações. Já, em outras filiais, estes espaços são chamados de maker corners por serem menor que a principal. No entanto, trazem os mesmos objetivos e o dia do fazer como atividade principal desses maker corners.

As programações do $R C$ e do makerspace são feitas em conjunto, no início do ano, com temas estratégicos como ambiente de inclusão social e datas americanas significativas. As atividades são feitas por esse calendário, contemplando workshops, oficinas, viagens de campo, programas sociais em parceria com a Embaixada Americana, atividades com escolas públicas e grupos carentes da comunidade, e treinamentos com tecnologias disponíveis no makerspace, tais como treinamento na cutter laser, impressora 3D, plotter, máquina de costura, colônia de férias. Existem inclusive atividades que são feitas em conjunto também as atividades de cada ambiente.

Enfatiza-se que é utilizado o design thinking na elaboração das atividades e na realização das dinâmicas. Todos envolvidos com a Casa Thomas Jefferson tiveram treinamento 
do método design thinking, uma vez que é muito utilizado. Os espaços contam com dois supervisores, um do makerspace e outro do $R C$, e dois assistentes.

O local é mantido pela Organização da Nações Unidas (ONU) e Embaixada Americana que patrocina seus projetos, material e transporte para alunos de escola pública para irem até a makerspace. Vale ressaltar que para a manutenção das máquinas é necessário pagar um valor pelo tempo de utilização, que é considerado acessível.

Para utilização do espaço maker, é necessário agendar um horário por telefone ou email, considerando que pode haver alguma atividade, aula, ou estar ocupado, visto que existem microempreendedores que utilizam o espaço com frequência. Não se tem uma noção em relação a frequência de utilização do local, pois varia muito. No entanto, as pessoas passaram a procurar mais esse espaço com o objetivo educacional.

O modelo mental de biblioteca mudou esse novo conceito, que traz uma definição mais pedagógica. Esse novo modelo faz com que a visão de makerspace como um todo dentro da biblioteca seja diferente, ou seja, a biblioteca com o espaço do fazer passa a mensagem de que a forma de aprender mudou. A forma de aprender engloba muito mais do que livros, estudos ou computadores, possibilitando o aprendizado de maneiras diferentes e através da experimentação.

\section{PROPOSTA DE GUIA PARA IMPLEMENTAÇÃO DE MAKERSPACE EM BIBLIOTECAS}

É primordial compreender que, para uma biblioteca ou unidade de informação se tornar uma makerspace, é necessário conhecer sobre a cultura maker e o seu significado. Para que possa assim criar um espaço que possibilite a aprendizagem através da experimentação, criatividade, troca de conhecimento e colaboração, características estas principais de um makerspace trazidos pela cultura maker.

A partir desta ideia, apresenta-se um guia preliminar de implementação de makerspace em bibliotecas, baseado na pesquisa bibliográfica e na análise de um caso prático real. O guia preliminar apresenta quatro etapas básicas informativas para implementação de $m a-$ kerspace em bibliotecas ou qualquer unidade de informação:

\section{- Passo 1: mudança de modelo mental}

a) Compreender o perfil da biblioteca e o objetivo, junto com missão, visão e valores;

b) Conhecer os usuários reais e em potencial, a comunidade e futuros parceiros;

c) Envolver todos, desde os usuários, a comunidade e a equipe de profissionais da unidade de informação;

d) Conscientizar e divulgação do novo modelo, por todos envolvidos.

Observação: É necessário o envolvimento das partes para que um novo modelo mental de biblioteca inovadora seja possível, para que o makerspace possa ser aceito, tanto pelos profissionais do local, usuários e comunidade quanto pelos parceiros.

\section{- Passo 2: desenvolvimento de atividades maker por toda biblioteca}

a) Aplicar atividades por todos ambientes da biblioteca e pela comunidade;

b) Conhecer e fazer parcerias com outras para trazer atividades de makerspace para o local; 
c) Visitar outras unidades de informação;

d) Pedir sugestões de todos para aplicação de atividades;

e) Desenvolver a criatividade como elemento principal.

Observação: É importante nesse passo fazer o marketing da biblioteca como makerspace com o apoio de todos.

\section{- Passo 3: criação do makerspace}

a) Envolver todas as pessoas;

b) Utilizar uma sala qualquer que possibilite o desenvolvimento de atividades;

c) Desenvolver no hall da biblioteca ou adaptar um local;

d) Iniciar com materiais mais simples, desde cola, papel, tesoura, papelão, massinha de modelar, jornal, componentes básicos eletrônicos, palitos de sorvete, madeira, canetinha, lápis de cor, isopor, giz de cera e argila, entre outros.

Observação: Não é necessário construir uma estrutura específica, poderá adaptar qualquer espaço, ficando a critério. No início, não há necessidade de entrar com equipamentos de alto custo, visto que a manutenção desses também é levada em conta.

\section{- Passo 4: obtenção de recursos}

a) Realizar parcerias com a comunidade para colaboração e voluntariado, no qual, sempre existe alguém que entende de certa coisa, equipamento ou atividade e que queira ajudar;

b) Formar parcerias com alunos que entendam também de tecnologia e de outras disciplinas, professores e profissionais diversos;

c) Criar parcerias com outras bibliotecas para troca de informações e doações ou troca de materiais;

d) Estabelecer parcerias com empresas e empresários que querem contribuir com uma causa social, objetivando conseguir apoio financeiro;

e) Instituir parceria com agências, editoras e livrarias;

f) Fazer parceria com instituições culturais, organizações governamentais, ONGs e centros comunitários.

Observação: É importante manter a inclusão da comunidade, pois esta pode auxiliar em algumas atividades, inclusive na utilização de tecnologias.

O desenvolvimento deste material pretende possibilitar um passo inicial de como implementar esses espaços, permitindo que qualquer pessoa que se interesse possa fazer um makerspace.

Para criação de uma makerspace é importante ter o envolvimento de pessoas em todos os processos, bem mais do que ter equipamentos. (NEVES, 2017).

Neves (2017) também explica que se a pessoa tem compreensão e atitude maker, desenvolver um trabalho diferencial é o fundamental. A disponibilidade e o uso de eletrônicos e máquinas, entre outros componentes, são importantes, contanto que tenha, pelo me- 
nos, um pouco criatividade envolvida, porque o indivíduo consegue construir uma máquina, porém, se tiver só a máquina sem saber o que fazer com ela, não se tem nada.

Acredita ainda que pessoas são mais relevantes, depois componentes eletrônicos e consumíveis básicos, que, às vezes, são coisas simples que podem ser encontradas no ambiente, mas que estão espalhadas.

As pessoas envolvidas também serão as mesmas que poderão facilitar os processos, considerando que a makerspace tem essa característica de colaboração. E makerspace em biblioteca permite que o desenvolvimento do conhecimento seja através da experimentação, colocando em prática toda informação adquirida através da leitura. Como também na criação de novas informações através da percepção desenvolvida no fazer, no construir, no elaborar coisas e compartilhar.

Tendo esses itens claros, constatamos que, para que uma biblioteca tenha makerspace ou a cultura para o movimento maker, é importante a mudança de comportamento do modelo mental tradicional de depositária para um modelo mais criativo e facilitado, para que possamos aceitar a inovação.

\section{CONSIDERAÇÕES FINAIS}

O processo deste estudo propiciou uma análise de como são implementadas makerspace em bibliotecas e de como surgiu esse conceito de makerspace e do seu significado, trazendo a importância quando inserido em instituições de informação e educação, centrando-se no espaço da biblioteca.

De modo geral, não se tem muitos dados de makerspace em bibliotecas no Brasil. Foram encontradas dificuldades em alcançar essas bibliotecas com makerspace, por não compreenderem a terminologia. Por este motivo, na interação com as bibliotecas contatadas, por vezes, o termo makerspace foi substituído por "espaço da criatividade", "espaço mão na massa", "espaço do fazer" e "sala de criatividade". Constatou-se que, em muitos casos, a biblioteca não dispunha desse espaço, no entanto, tinham interesse em conhecer mais sobre o assunto. Em outros casos, já possuíam conhecimento sobre o tema e estavam trabalhando para levar à biblioteca um novo conceito de inovação, entre eles o espaço maker, porém, ainda não atendiam o perfil.

Através da análise dos estudos identificados, foi possível constatar a relevância desses espaços inseridos na biblioteca, sendo tanto o makerspace quanto a biblioteca dois potencializadores de um conceito de biblioteca mais atrativo, estimulante e facilitador da informação, que atua promovendo a educação e a experimentação. Além disso, tratou-se de despertar uma nova concepção existente em outros países e de grande valia em várias questões.

As principais informações coletadas sobre o processo de implementação do makerspace na Biblioteca da Casa Thomas Jefferson, esclareceu que, antes da criação de um espaço maker, é preciso compreender a abrangência do conceito. Além de envolver todos os indivíduos que trabalham e que participam da biblioteca para um novo modelo mental, através de aplicações de atividades utilizando todos espaços da biblioteca.

Partindo da conscientização de que a biblioteca está mudando seu conceito do sentido tradicional para inovador de forma que o conhecimento seja facilitado, o makerspace poderá ser criado. 
Tendo em vista a relevância e atualidade do tema, destaca-se como proposta de estudos futuros a ampliação da análise para casos reais no âmbito internacional se faz necessária.

\section{REFERÊNCIAS}

ABDO, H.; AMARAL, L. Penso no movimento maker como um tipo de renascença, afirma dale dougherty. Estadão Jornal Digital, [20--?]. Disponível em:

http://infograficos.estadao.com.br/e/focas/movimento-maker/dale-dougherty.php\#. Acesso em: 17 nov. 2017.

AMBROSE, G.; HARRIS, P. Design thinking: s.m. ação ou prática de pensar o design. Porto Alegre: Bookman, 2011.

BORGES, K. S.; MENEZES, C. S.; FAGUNDES, L. C. Projetos maker como forma de estimular o raciocínio formal através do pensamento computacional. In: CONGRESSO BRASILEIRO DE INFORMÁTICA NA EDUCAÇÃO, 5., 2016, Uberlândia. Anais... Uberlândia: SBC, 2016. Disponível em: http://dx.doi.org/10.5753/cbie.wie.2016.515. Acesso em: 20 jan. 2019.

BROWN, T. Design thinking: uma metodologia poderosa para decretar o fim das velhas ideias. Rio de Janeiro: Elsevier, 2010.

CARDINS, J. S. C.; SILVA, L. F. O.; NICOLAU, M. inteligência coletiva no ciberespaço: questões de direitos autorais frente à cultura do faça-você-mesmo no contexto dos blogs. In: CONGRESSO BRASILEIRO DE CIÊNCIAS DA COMUNICAÇÃO, 35., 2012, Fortaleza. Anais... Fortaleza: Intercom, 2012. Disponível em: http://www.intercom.org.br/sis/2012/resumos/R7-14981.pdf. Acesso em: 20 nov. 2018.

CAVALCANTI, G. Is it a Hackerspace, Makerspace, TechShop, or FabLab? Make, 2013. Disponível em: https://makezine.com/2013/05/22/the-difference-between-hackerspacesmakerspaces-techshops-and-fablabs/. Acesso em: 20 jan. 2018.

GALLO, I. Por uma historiografia: do punk. Revista do Programa de Pós-Graduação em História, v. 41, ago./dez. 2010. Disponível em: https://revistas.pucsp.br/revph/article/view/6542/4741. Acesso em: 10 nov. 2018.

HATCH, M.; CAVALLINI, R. Os makers debatem a última fronteira do: faça-você-mesmo. HSM Management, ed. 105, 2014. Disponível em: http://makers.net.br/wpcontent/uploads/2014/07/24-30 Makers-final.pdf. Acesso em: 17 nov. 2017.

HATCH, M. The maker movement manifesto: rules for innovation in the new world of crafters, hackers, and tinkers. New York: Mc Graw Hill, 2014. Disponível em: http://www.boerneneshovedstad.dk/media/1332/maker-movement-manifesto-samplechapter.pdf. Acesso em: 20 out. 2018.

LITTS, B. K. Making learning: Makerspaces as learning environments. 2015. Dissertation (Doctor of Philosophy) - University of Wisconsin-Madison, 2015. Disponível em: 
http://www.informalscience.org/sites/default/files/Litts 2015 Dissertation Published.pdf. Acesso em: 20 out. 2017.

LUMLEY, R. M. A Coworking Project in the Campus Library: supporting and modeling entrepreneurial activity in the Academic Library. New Review of Academic Librarianship, v. 20, n. 1, 2014. Disponível em: http://dx.doi.org/10.1080/13614533.2013.850101. Acesso em: 20 nov. 2018.

MACEDO, P. A.; SANTOS, A. M. S. Design Thinking para Bibliotecas. In: PRADO, J (Org.). Ideias emergentes em Biblioteconomia. São Paulo: FEBAB, 2016. p. 69-77. Disponível em: http://www.febab.org.br/febab201603/wp-content/uploads/2016/07/Ideias-EmergentesEm-Biblioteconomia.pdf. Acesso em: 20 nov. 2018.

MARAVILHAS, S.; MARTINS, J. Fab Labs: estímulo a inovação, usando a fabricação digital. 2016. Revista GEINTEC: gestão, inovação e tecnologia, v. 6, n. 4, p.3499-3514, 2016. Disponível em: http://www.revistageintec.net/index.php/revista/article/view/1046. Acesso em: 16 nov. 2017.

MARTIN, R. L. Design de negócios: porque o design thinking se tornará a próxima vantagem competitiva dos negócios e como se beneficiar disso. Rio de Janeiro: Elsevier, 2010.

MARTINS, B. C. Hackerspaces, ciência cidadã e ciência comum: apontamentos para uma articulação. 2017. Liinc em Revista, Rio de Janeiro, v. 13, n. 1, p. 59-71, maio 2017. Disponível em: http://dx.doi.org/10.18617/liinc.v13i1.3752. Acesso em: 15 nov. 2017.

VIANNA, M.; VIANNA, Y.; ADLER, I. K.; LUCENA, B. F.; RUSSO, B. Design thinking: inovação em negócios. Rio de Janeiro: Mjv Press, 2012. 